\title{
Hegemonia compartilhada e organizações internacionais: a proposta trilateralista dos anos de $1970^{1}$
}

\section{Shared hegemony and international organizations: the trilateralist proposal of the 1970's}

DOI: $10.21530 /$ ci.v12n2.2017.627

Rejane Hoeveler ${ }^{2}$

\section{Resumo}

No início dos anos de 1970, a criação da Trilateral Commission, composta por intelectuais, empresários e políticos de Estados Unidos, Japão e Europa Ocidental, trazia uma nova perspectiva estratégica em um mundo atribulado por disputas comerciais e políticas dentro do bloco capitalista. Inspirada e formulada por intelectuais como Zbigniew Brzezinski, ela teve como um de seus temas centrais a reformulação das instituições internacionais, vistas por eles como conturbadas por uma confrontação cada vez maior por parte de coalizões de países do então chamado Terceiro Mundo. A Trilateral Commission reunia algumas figuras-chave de instituições como o Fundo Monetário Internacional e o Banco Mundial, e suas propostas para a reformulação dessas e de outras instituições vinham no sentido de "despolitizá-las", criando mecanismos permanentes de prevenção de conflitos internacionais. Para estrategistas como Brzezinski, essa era uma forma de recompor a hegemonia americana que, confrontada pela "síndrome do Vietnã" e com a crise do petróleo, parecia agora aceitar a ideia de uma "hegemonia compartilhada”. O propósito do artigo é mostrar como as propostas trilateralistas para o funcionamento das organizações internacionais foram uma das principais alternativas estratégicas desenvolvidas naquele contexto histórico.

Palavras-chave: Organizações internacionais; Comissão Trilateral; Hegemonia; teoria neogramsciana

\footnotetext{
Abstract

In the early 1970s, the creation of the Trilateral Commission, made up of intellectuals, entrepreneurs, and politicians from the United States, Japan, and Western Europe, brought a new strategic perspective into a world beset by trade and political disputes within the capitalist

1 Este artigo é parte de pesquisa financiada pela CAPES.

2 Departamento de História da Universidade Federal Fluminense, Niterói/RJ, Brasil. E-mail: rejanecarol@gmail.com Artigo submetido em 08/02/2017 e aprovado em 08/05/2017.
} 
bloc. Inspired and formulated by intellectuals such as Zbigniew Brzezinski, it had as one of its central themes the reformulation of international institutions, which they saw as being disturbed by a growing confrontation by the coalitions of countries of the Third World. The Trilateral Commission brought together key figures from institutions such as the International Monetary Fund and the World Bank, and its proposals for the reformulation of these and other institutions came in the direction of "depoliticizing” it, by creating mechanisms for a permanent prevention of international conflicts. For strategists like Brzezinski, this was a way of re-establishing american hegemony which, faced with the "Vietnam syndrome" and the oil crisis, now seemed to accept the idea of "shared hegemony." The purpose of the article is to demonstrate the trilateralist proposals for the functioning of international organizations as one of the most important strategic alternatives developed in that historical context.

Keywords: International organizations; Trilateral Commission; Hegemony; neogramscian theory

“A prevenção de conflito é melhor que a resolução de conflito; e as aspirações a um sistema internacional devem ir além de meramente lidar com problemas futuros para moldar esses eventos.” (COOPER, KAISER \& KOSAKA, 1977, p. 200)

A Trilateral Commission, criada em 1973, foi fruto de iniciativa de estrategistas norte-americanos num contexto em que a hegemonia global dos Estados Unidos parecia estar fundamentalmente em xeque. A crise econômica mundial, com alta inflação combinada à estagnação, os “choques” do petróleo e a onda mobilizatória - que varreu o mundo em 1968 - somaram-se, no caso americano, a uma forte oposição à escalada da Guerra do Vietnã. “Trilateral” foi o nome escolhido por seus criadores por se tratar de uma proposta de aliança entre as três regiões do mundo consideradas industriais e democráticas (ou "sociedades trilaterais”, no linguajar da comissão): Estados Unidos, Japão e Europa Ocidental. A ideia básica da comissão era que deveria haver uma firme e consistente ação conjunta dessas três regiões, mas a comissão se definia como uma iniciativa de cidadãos individuais, e não de governos ou empresas - embora a presença de burocratas de Estado, bem como de empresários, fosse bastante grande na comissão, juntamente com a dos intelectuais, em especial economistas e teóricos de relações internacionais ${ }^{3}$.

Procuraremos mostrar neste artigo que o viés institucionalista e liberal da Trilateral Commission, presente no pensamento dos intelectuais ligados a ela, em

3 Os dois grandes impulsionadores da comissão foram David Rockefeller, magnata americano do petróleo e das finanças, e o sovietólogo Zbigniew Brzezinski, estrategista, à época, já bem conhecido nos círculos diplomáticos dos Estados Unidos. 
especial economistas e teóricos de relações internacionais, marcou profundamente suas propostas de reforma das organizações internacionais. Também demonstraremos que os chamados trilateralistas não estavam preocupados com mudanças de curto prazo, mas sim com formatos institucionais de longa duração, que deveriam atender à necessidade de viabilizar as negociações internacionais de maneira a “despolitizar” os conflitos de forma relativamente permanente. Demonstraremos que tais propostas tiveram grande relevância entre importantes empresários, políticos e burocratas de Estado da época, e que, por isso, a proposta trilateralista foi a mais elaborada alternativa estratégica colocada naquele contexto de crise de hegemonia internacional. Pretendemos demonstrar essa relevância através da análise dos atores políticos envolvidos nesse projeto, bem como de sua influência direta e indireta em organismos como o Banco Mundial e a Agência Internacional de Energia. Nosso objetivo não será provar a influência direta da comissão em casos específicos de reformas de organizações internacionais, embora façamos referências a alguns deles, mas sim demonstrar a relação entre o pensamento e a ação política que tornaram possível o surgimento da proposta trilateralista.

Embora a comissão tenha ficado mais famosa por seu relatório sobre a crise das democracias (HUNTINGTON, CROZIER \& WATANUKI, 1975), em seu bojo foram formuladas propostas relativas a numerosos temas, com destaque para a crise do petróleo, a crise do sistema monetário internacional e a reforma das instituições internacionais - esta última, pouquíssimo visitada na literatura especializada, com raras exceções (BONHOMME, 2014) . Empenhados em uma reavaliação geral da diplomacia americana dos anos de 1950 e 1960, os intelectuais ligados à comissão, como Zbigniew Brzezinski, procurariam desenvolver um quadro compreensivo e normativo para a política externa dos Estados Unidos (BRZEZINSKI, 1971). Embora o tema das organizações internacionais tenha sido um dos mais discutidos no âmbito da Trilateral Commission desde seu início, em 1973, os primeiros relatórios sistemáticos sobre o assunto seriam publicados apenas a partir de 1976 - ano no qual as eleições nos Estados Unidos consagrariam o democrata “Jimmy” Carter na presidência, ele próprio um membro da Trilateral Commission (SKLAR, 1980; GILL, 1990).

Este artigo, portanto, pretende tratar do tema das organizações internacionais, tão caro entre os estudiosos de relações internacionais, a partir de uma análise

4 O último estudo relevante sobre a Trilateral Commission foi o trabalho de Stephen Gill (1990), onde a questão da reforma das instituições internacionais não é pormenorizada. 
histórica do chamado trilateralismo, não somente apresentando detalhadamente os principais aspectos de suas propostas para o formato das instituições internacionais, como também demonstrando a íntima relação dessas com determinadas teorias bastante influentes no campo das relações internacionais - como, por exemplo, o conceito de "interdependência complexa" de Joseph Nye e Robert Keohane. Nesse sentido, o artigo procura se inserir no frutífero reconhecido diálogo existente entre o campo da história e o das relações internacionais. Numa época em que relevantes organizações internacionais como a União Européia parecem quebrar, e em que se procura entender uma nova crise de hegemonia internacional, acreditamos ser útil revisitar as propostas e experiências de reforma de organizações internacionais dos anos de 1970.

\section{Organizações internacionais e crise de hegemonia: uma visão a partir da teoria crítica}

Muito embora a criação da Organização das Nações Unidas (ONU) e do complexo de instituições internacionais que conformou o chamado sistema de Bretton-Woods já tivesse despertado o interesse no estudo acerca das organizações internacionais, é somente na década de 1960, mas principalmente na de 1970, que proliferam os estudos nesse campo. Segundo Herz e Hoffman, ocorre uma separação analítica, na década de 1960, entre o debate acerca dos mecanismos de estabilização do sistema internacional e os estudos sobre o papel das organizações internacionais, a fim de desvendar a função específica das Organizações Intergovernamentais Internacionais (OIGs) (HERZ; HOFFMAN, 2004, p. 45). Nessa geração de estudos, diversos temas teriam sido tratados, como segurança nuclear, "assistência aos processos de descolonização" e "ajuda ao desenvolvimento". Esses estudos, em geral, eram críticos da chamada teoria realista, que considerava o Estado como único e indivisível ator nas relações internacionais.

Na década seguinte, dois dos maiores focos dos estudos sobre organizações internacionais foram as relações Norte-Sul e os problemas do meio ambiente. Segundo Herz e Hoffman, uma orientação marcante nessa bibliografia dos anos de 1970 é a relação entre a constituição do sistema internacional e o papel das organizações internacionais. Os fóruns para a formação de coalizões e as formas de coordenação de políticas transgovernamentais seriam algumas das funções das organizações internacionais abordadas nesse contexto (HERZ; HOFFMAN, 2004, p. 46). É desse período o conhecido trabalho de Robert Cox e de Harold 
Jacobson sobre oito agências especializadas da ONU (COX; JACOBSON, 1973). O papel das organizações internacionais após a Segunda Guerra Mundial, segundo os trabalhos posteriores de Cox, teria sido fundamental para a universalização das normas compatíveis com o hegemon da pax americanna.

A ideia de hegemon e de hegemonia para o sistema internacional foi desenvolvida por diversos autores inspirados nos escritos do filósofo sardo Antonio Gramsci (1891-1937). Em seu O longo século XX, por exemplo, Giovanni Arrighi constrói um grande painel da história do capitalismo entre os séculos XVI e XX, buscando demonstrar que tal trajetória histórica teria sido marcada por aquilo que chama de "ciclos sistêmicos" de acumulação mundial, onde um país assumiu a posição de centro hegemônico do sistema internacional. O sociólogo italiano observa que alguns dos fenômenos observados a partir dos anos de 1970 - que ele e autores como Immanuel Wallerstein (2004) consideram sintomas do fim da hegemonia dos EUA, como a financeirização e a constituição de uma nova divisão internacional do trabalho - são características encontráveis em situações anteriores que marcaram o fim das hegemonias do sistema internacional do capitalismo histórico (ARRIGHI, 1996).

Por sua vez, a análise de Cox sobre as organizações internacionais se revela bastante instigante, pois o autor entende que essas desempenham papéis fundamentais em uma ordem mundial hegemônica, como: "corporificar as regras que facilitam a expansão das ordens mundiais hegemônicas"; "legitimar ideologicamente as normas da ordem mundial”; "cooptar as elites dos países periféricos"; e "absorver ideias contra-hegemônicas” (COX, 2007). Nas palavras de Cox,

As instituições internacionais corporificam regras que facilitam a expansão das forças econômicas e sociais dominantes, mas permitem simultaneamente aos interesses subordinados fazerem ajustes com um mínimo de desgaste. (COX, 2007, p. 119)

O sistema hegemônico construído no pós-Segunda Guerra Mundial, que incluiu a formatação de todo um sistema de organizações intergovernamentais, parecia ter chegado a um esgotamento. As organizações internacionais moldadas no período da chamada pax americanna não poderiam passar incólumes por essa crise de hegemonia, marcada, entre outros fatos, pelo surgimento de diversos tipos de coalizões de países do Terceiro Mundo5.

5 Estamos utilizando a expressão Terceiro Mundo de maneira meramente descritiva. 
Cox localiza entre fins dos anos de 1960 e início da década de 1970 o fim daquilo que ele denominou "Estado neoliberal" da Pax Americanna, constituído após o fim da Segunda Guerra Mundial'b, uma forma de Estado que tinha determinados papéis no bloco de forças sociais dentro dos Estados nacionais. O autor considera o contexto de fins dos anos de 1960 e início dos anos de 1970 como fundamentalmente não hegemônico, e localiza nesse período um ponto de virada. A crise da hegemonia americana teria provocado a necessidade de uma nova e modificada estrutura institucional. Essa crise, segundo Cox, teria gerado a necessidade da construção de um novo consenso hegemônico, que teria que refletir necessariamente não apenas o novo peso econômico e político da Alemanha Ocidental e do Japão, bem como levar em conta a ascensão de um conjunto significativo de nações recentemente industrializadas.

Como veremos, o projeto trilateralista é expressivo dessa busca, que, longe de ser uma tendência inata ao sistema, depende da atuação dos atores políticos internacionais. Conforme o próprio Cox enfatiza, o papel da agência dos atores políticos, embora esteja sempre condicionado, em algum grau, por fatores objetivos, é fundamental para compreender o desenlace dos conflitos internacionais.

Ao contrário do que encontramos em grande parte da literatura sobre as relações internacionais, a hegemonia é aqui considerada não somente como uma relação interestatal, mas como a penetração de um modo dominante de desenvolvimento.

Discutindo o conceito de hegemonia em Gramsci, Cox procurou aprofundar teoricamente o uso desse conceito para as relações internacionais, sem reduzilo ao uso comum da ideia de hegemonia como mera "supremacia" (no sentido de superioridade bélica). Um dos pontos mais enfatizados tanto por Cox quanto por outros autores chamados "neogramscianos" como Stephan Gill, é que "a hegemonia deriva dos estratos sociais dominantes dos Estados dominantes, desde que essas maneiras de agir e pensar tenham obtido a aquiescência dos estratos sociais dominantes de outros Estados” (GILL, 2007, p. 91-92). Tal ponto é fundamental para nosso estudo, já que consideramos o trilateralismo, junto com Gill, como um projeto proveniente dos estratos dominantes dos Estados mais poderosos, preocupados em garantir instituições internacionais asseguradoras de consentimento de países menos poderosos - ou, ao menos, de suas elites políticas.

6 Note-se que o termo "neoliberal" em Cox não se refere ao que comumente entendemos como neoliberalismo (teoria associada a nomes como Milton Friedman ou F. A. von Hayek), mas diz respeito exatamente ao tipo de liberalismo que vigorou no pós-Segunda Guerra, embutido de políticas keynesianas. 
Vale assinalar que, para Cox, num sistema hegemônico o conflito não é propriamente "eliminado", mas regulado e institucionalizado, e, muito importante, "a institucionalização do conflito dentro da potência dominante torna-se base para essa institucionalização também no plano global” (GARCIA, 2012, p. 202). A proposta trilateralista representa exatamente essa institucionalização preventiva do conflito internacional.

Tendo essas reflexões em mente, veremos agora quais foram as formulações elaboradas no bojo da Trilateral Commission, bem como o debate acerca delas dentro da entidade, que revelou inúmeras divergências. Analisaremos como o tema das organizações internacionais foi tratado pela comissão desde seus primeiros anos de existência; e, em seguida, examinaremos os três Task Force Reports (doravante TFRs) que a comissão publicou entre 1976 e 1977 sobre a reforma do sistema internacional, detalhando seus diagnósticos e receituários ${ }^{7}$. Alertamos que as notas com a descrição dos autores envolvidos na elaboração dos TFRs, embora longas, se fazem necessárias para demonstrar a relevância dos atores intelectuais, políticos e econômicos envolvidos na elaboração trilateralista, requisito essencial para a demonstração da hipótese apresentada.

\section{Trilateral: um projeto cosmopolita, liberal e institucionalista}

Desde o início de seus trabalhos, a Trilateral Commission visava a construção de uma hegemonia de novo tipo, modificando a arquitetura do sistema internacional. Já no TFR número 3, de 1974, era afirmado que tanto os países desenvolvidos quanto os países em desenvolvimento deveriam dar maior peso, em sua policy making, para sua "crescente interdependência"; para os trilaterais, isso significaria que a assistência e as medidas comerciais em favor dos países em desenvolvimento não deveriam ser tomadas apenas porque era "o certo", mas porque o "mundo trilateral” necessita crescentemente dos países em desenvolvimento como fontes de matérias-primas e como mercados de exportação (GARDNER, OKITA \& UDINK,

7 Os Task-Force Reports da Trilateral Commission - ou “relatórios de força-tarefa”, em tradução literal - eram densos estudos, escritos em geral ao longo de meses ou mesmo anos de consultas, quase sempre com autores especialistas nas temáticas em estudo, e provenientes das três regiões “trilaterais” (Estados Unidos, Japão e Europa Ocidental). Outra publicação importante da comissão eram os Trialogues, boletins mais curtos, de periodicidade trimestral, nos quais se descrevia os avanços alcançados nos objetivos da comissão, bem como a repercussão dos Task-Force Reports (TFRs) nas três regiões. Todas as passagens aqui citadas dessas fontes foram traduzidas por nós dos originais em inglês, que estão disponíveis no sítio eletrônico da entidade (www.trilateral.org). 
1974, p. 19). O principal autor do relatório, Richard Gardner, era um economista reconhecido nos Estados Unidos, tendo participado de conselhos governamentais e também de think tanks como a Brookings Institution. Seu pensamento estava fortemente marcado pela necessidade de construir instituições econômicas internacionais sólidas.

O novo sistema de relação entre os países, segundo a Trilateral, deveria respeitar o direito de independência e equidade sob a lei internacional para todos os membros da comunidade internacional, pobres e ricos, pequenos e grandes. O relatório dizia rejeitar também a existência de políticas especiais de comércio e assistência, que enlaçavam a África à Europa, a América Latina aos EUA, e o Sudeste Asiático ao Japão - continuidades dos antigos sistemas coloniais.

Nós precisamos evitar a tentação que há nos países trilaterais em um período de escassez de recursos a concentrar sua ajuda e favores comerciais em um grupo relativamente pequeno de países em desenvolvimento ricos em recursos enquanto ignora as necessidades do resto. (GARDNER, OKITA \& UDINK, 1974, p. 21)

A preocupação exposta nesse relatório mostra o viés liberal da proposta trilateralista, em sua defesa de que um genuíno livre-comércio favoreceria as nações e o sistema internacional como um todo - tema presente no pensamento ocidental desde a economia política clássica (especialmente Adam Smith e David Ricardo). Complementando o viés liberal, encontramos a visão institucionalista que reforça a necessidade de organizações econômicas e políticas internacionais fortes para regular os conflitos.

Como se sabe, a abordagem funcionalista de relações internacionais desenvolveu uma alternativa ao liberalismo do início do século, mantendo sua confiança no progresso e na cooperação internacional, mas acentuando que esses eram possíveis a partir da busca pela maximização dos benefícios materiais com menores custos. Nessa concepção, a cooperação nas organizações internacionais, preferível à competição por ser mais eficiente na conquista desses benefícios, geraria um efeito gradual de transbordamento (spill-over effect), no qual o sucesso de determinada forma de cumprimento de um objetivo ou função "transborda" para as demais áreas. O neofuncionalismo influenciaria claramente as teorias de Nye e Keohane (NOGUEIRA; MESSARI, 2005, p. 78; HERZ, 1997). 


\section{Interdependência complexa e organizações internacionais}

Mas foi apenas no décimo primeiro Task-Force Report da comissão, intitulado “A reforma das instituições internacionais”, e assinado por C. Fred Bergsten", Georges Berthoin ${ }^{9}$ e Kinhide Mushakoji10, que o tema da estrutura das instituições internacionais receberia atenção exclusiva. Apresentado e discutido na plenária geral da Trilateral Commission na capital canadense Ottawa, entre 9 e 11 de maio de 1976, o processo de elaboração do relatório contou com a colaboração de diversos nomes academicamente relevantes, como Robert Keohane, da Universidade de Stanford - um importante autor das relações internacionais -, Hayward Alker, do Massachussets Institute of Tecnology (MIT), e Donald Puchala, da Universidade de Columbia; e ocupantes de cargos políticos, como Thierry de Montbrial, chefe do Centro de Análise e Previsão do Ministério das Relações Exteriores da França. Os rascunhos do relatório foram discutidos em várias reuniões ocorridas entre dezembro de 1974 e junho de 1976.

O pressuposto do relatório era que o objetivo mínimo da organização internacional deveria ser ajudar a "evitar ações nacionais unilaterais" que ferem "a humanidade como um todo". Por isso, as instituições internacionais deveriam ajudar a "distribuir os custos e benefícios das ações internacionais” entre as nações envolvidas em um arranjo aceitável, assim como promover políticas desejáveis para atingir esses objetivos fundamentais (BERGSTEN, BERTHOIN \&

8 Economista ligado à Brookings Institution, trilateralista de primeira hora, C. Fred Bergsten era também membro do Council on Foreign Relations (CFR), o mais tradicional think tank de política externa dos Estados Unidos, onde a própria ideia da Trilateral Commission foi gestada. Bergsten chegou a ser membro do National Security Council sob a gestão Kissinger, onde dirigiu um grupo de discussão durante 1972 e 1973 intitulado "American interests in the Third World”, e continuou como o líder da discussão de um grupo similar no CFR entre 1974-75. De forma similar a Brzezinski, outro fundador da Comissão, Bergsten criticava a negligência da administração de Nixon em relação ao Terceiro Mundo e seu tratamento dessas regiões do globo como meros "peões no xadrez da política global”. Os argumentos de Bergsten nessa crítica à política externa kissingeriana enfatizavam a enorme importância do Terceiro Mundo como fornecedor de uma série de recursos para os países centrais, em especial os Estados Unidos, e também como receptor de investimentos americanos. Tanto para Brzezinski como para Bergsten, a política externa americana de então não estava levando em consideração tal relevância.

9 Representante-chefe da Comissão das Comunidades Européias no Reino Unido entre 1971 e 1973, ano em que a Inglaterra entra na comunidade, Berthoin começou sua carreira no serviço público francês como secretário do Ministério das Finanças. Após um período como chefe de equipe da subprefeitura de Alsácia-Lorena-Champagne, ele entrou para o serviço público europeu e serviu como primeiro secretário privado de Jean Monnet, então presidente da Alta autoridade da ECSC (European Coal and Steel Community), na qual passou a ocupar o cargo de representante em Londres em 1956.

10 K. Mushakoji, que fez carreira acadêmica em Bruxelas e Paris, na área de Ciência Política, foi diretor do Instituto de Relações Internacionais para estudos avançados sobre a paz e o desenvolvimento na Sophia University entre 1969 e 1975. Na época do relatório, era vice-reitor de programas da Universidade das Nações Unidas em Tóquio. 
MUSHAKOJI, 1976, p. 1). Mais uma vez, o viés institucionalista da proposta trilateralista fica claro.

Segundo o relatório, uma grande lição do passado é que as instituições internacionais podem tornar o mundo "seguro para a interdependência" e que, de fato, são necessárias para evitar esforços de nações individuais de "exportar" seus problemas internos umas para as outras. Diante disso, todas as questões da interdependência internacional deveriam ser trazidas junto à "governança de regras" e "arranjos internacionais efetivos". Para Bergsten, Berthoin e Mushakoji, atingir os objetivos das instituições internacionais se tornou mais complexo do que nunca por causa da intensidade e da extensão do padrão de interdependência entre as nações.

O termo "interdependência” já se fazia presente na literatura econômica do período; mas foi o conceito de interdependência complexa, tal como desenvolvido por Joseph Nye e Robert Keohane desde 1971, que se fez presente em maior ou menor medida nos relatórios aqui analisados - uma prova cabal da relação simbiótica entre as teorias de relações internacionais e as propostas normativas colocadas para as organizações internacionais. Como se sabe, a interdependência complexa se referia a uma situação entre uma série de países nos quais múltiplos canais de contato conectam as sociedades (ou seja, os Estados não monopolizam esses contatos), em que não há uma hierarquia de questões e em que a força militar não é utilizada pelos governos uns contra os outros. Ao analisar a política da interdependência, os autores enfatizaram que a interdependência não levaria necessariamente à cooperação, nem que suas consequências seriam automaticamente benignas (KEOHANE; NYE, 1971).

O tema da interdependência complexa aparece com proeminência em outro TFR sobre o tema das instituições internacionais: o TFR 14, "Em direção a um sistema internacional renovado", a cargo de Richard Cooper ${ }^{11}$, Karl Kaiser ${ }^{12}$ e Masataka Kosaka ${ }^{13}$. Embora só publicado em 1977, a elaboração do relatório começou ainda em dezembro de 1974, com uma sessão preliminar em Washington que incluiu Z. Brzezinski e 22 outros comissionários.

11 Economista Sênior no Council of Economic Advisers entre 1961 e 1963, e Deputy Assistant Secretary of State for International Affairs entre 1965 e 1966, publicou em 1968 The Economics of Interdependence (1968); na época do relatório, era diretor de Yale University.

12 Diretor do tradicional Instituto de Pesquisa da Sociedade Alemã para Política Externa.

13 Professor de Direito da Universidade de Kyoto, pesquisador associado ao International Institute for Strategic Studies de Londres, e estudioso da política externa japonesa. 
Entre os aspectos negativos da interdependência, segundo os autores, estariam as ameaças de proliferação nuclear e de nocivas mudanças ambientais, juntamente com a extrema pobreza, especialmente no sul da Ásia e em partes da África. A ideia forte aqui era a de que, em longo prazo, um “mundo com ordem” não seria provável se uma grande afluência em algumas regiões continuasse a coexistir com a pobreza abjeta em outras - cenário agravado já que a comunicação entre todas as partes crescia exponencialmente, permitindo aos pobres tomar conhecimento pleno sobre a opulência das parcelas privilegiadas (COOPER, KAISER \& KOSAKA, 1977, p. 180-190).

Para os autores do relatório de 1976, liderados por C. F. Bergsten, teria havido três grandes fases na construção de instituições internacionais. Cada uma delas teria tido dois objetivos: a ratificação e legitimação da estrutura de poder subjacente às relações internacionais no período, e a inserção de novos integrantes (newcomers) nessas relações. Em 1945, isso teria significado basicamente codificar a hegemonia americana e envolver os outros Estados-nações independentes, com exceção dos comunistas (entendidos como dropouts - aqueles que "pularam fora”). Em torno de 1960, isso significava um papel maior para a Europa Ocidental e o Japão, e a incorporação de países recentemente independentes da Ásia e da África.

Das lições sobre a história das organizações internacionais, segundo o relatório, poder-se-ia depreender que a própria existência de tais instituições internacionais, mais do que as regras específicas, é o que “inspira confiança” tanto nos setores públicos como governamentais - principalmente a "confiança” de que o progresso não será quebrado pelo conflito entre as nações. Os acordos internacionais fortaleceriam as forças de visão global (outward-looking) dentro de cada governo nacional (BERGSTEN, BERTHOIN \& MUSHAKOJI, 1976, p. 4). Podemos facilmente contrastar essa visão sobre o papel das organizações internacionais com a visão da teoria crítica de Cox e Gill: na ideia de interdependência, desaparecem as relações de dominação entre países e classes, entrando em seu lugar "assimetrias" a serem “manejadas" pela institucionalidade internacional.

\section{A “politização” nas organizações internacionais}

Outra lição da história, segundo o relatório, seria que organizações internacionais específicas funcionariam muito melhor que organizações com múltiplos propósitos para atingir metas concretas. Isso seria mais claro para 
questões essencialmente "não políticas", como a União Postal Internacional ou a OMS (Organização Mundial de Saúde). Mas também seria válido para instituições econômicas específicas, como o GATT (General Agreement on Tariffs and Trade) e o FMI (Fundo Monetário Internacional), quando comparadas a agências maiores das Nações Unidas (BERGSTEN et al., 1976, p. 5). A ligação de áreas de questões distintas (issue-area linkage) e a politização - ambas consideradas "prejudiciais ao progresso" de negociações internacionais - seriam mais bem evitadas nessas organizações. A indesejada ligação ocorreria quando países individuais atam o progresso em uma questão à solução de outras questões, como "preço" para sua cooperação ${ }^{14}$.

A politização também seria evitada em instituições específicas por conta do suposto consenso de que essas instituições são as melhores, talvez as únicas, em que "acordos sérios" poderiam ser feitos. Nas palavras do relatório, os mesmos países que iriam "esbravejar retoricamente" em organizações multipropositais, como nas várias agências das Nações Unidas, poderiam ao mesmo tempo negociar "séria e cooperativamente" em outras estruturas mais focadas em determinada questão. Nas palavras dos autores, "o foco mais técnico, e menor atenção pública, de tais organizações promovem esse resultado" (BERGSTEN, BERTHOIN \& MUSHAKOJI, 1976, p. 6, grifo nosso)

Não obstante, de acordo com o relatório, as organizações multipropositais, como a ONU, também teriam um importante papel a cumprir, pois elas poderiam, muito melhor que instituições específicas, legitimar esses novos conceitos internacionais. Elas poderiam coordenar as atividades de muitas organizações específicas e permitir aos governos nacionais que transmitam suas preocupações políticas, sem medo de desencaminhar o progresso das "metas objetivas" (BERGSTEN, BERTHOIN \& MUSHAKOJI, 1976, p. 6). Em suma, tratava-se de deslocar as instâncias centrais de decisão das grandes agências multipropositais para as inúmeras agências "especializadas" e "despolitizadas", diluindo assim os focos de conflito; mas manter organizações como a ONU como suporte para geração de consenso e legitimação do sistema internacional.

Ainda segundo o relatório, a politização da economia internacional residiria na própria lógica dos "Estados modernos de bem-estar [social]". Ao mesmo tempo, para os países em desenvolvimento mais fracos,

14 A articulação entre questões, segundo o relatório, vinha sendo um traço comum de negociações dentro da Comunidade Europeia, e dentro de todas as principais negociações comerciais no pós-Segunda Guerra. 
a interdependência aparece como um sistema de dependência. Daí o apelo de teorias que enfatizam elementos de dependência na economia mundial, incluindo as corporações multinacionais, e as quais formam a base para grande parte da retórica, senão da estratégia política, de muitos países em desenvolvimento. (COOPER, KAISER \& KOSAKA, 1977, p. 191, grifo nosso) ${ }^{15}$

Era por esse motivo, segundo o relatório, que alguns intelectuais, grupos e governos no Terceiro Mundo crescentemente advogavam uma “estratégia dissociativa” entre Norte e Sul. A cooperação requisitada tanto a curto como a longo prazo, segundo os autores, deveria estar baseada na convicção compartilhada que ela "maximiza o ganho geral" e "aumenta o bem-estar dos envolvidos". O papel das instituições, em especial do Banco Mundial, nesse quesito era considerado fundamental pela possibilidade de, através dele, garantir “assistência” no combate à “pobreza absoluta”.

A gestão de McNamara no Banco Mundial, cujo escopo ideológico ficou bem expresso em seu discurso de 1973 sobre a justiça social como um imperativo político, coadunava-se com os pressupostos trilateralistas (PEREIRA, 2010). A parceria dessa organização com a Trilateral começou com a participação do então presidente do banco, Robert McNamara, em diversas reuniões da comissão, culminando na elaboração, entre 1976 e 1978, de um relatório especial sobre agricultura na Ásia. O TFR escrito por Umberto Colombo ${ }^{16}$, D. Gale Johnson ${ }^{17}$ e Toshio Shishido18 intitulava-se "Reduzindo a desnutrição em países em desenvolvimento: aumentando a produção de arroz no Sul e Sudeste da Ásia”, e foi discutido na plenária da comissão em Bonn, entre 22 e 25 de outubro de 1977, com diversos especialistas do Banco (COLOMBO, JOHNSON \& SHISHIDO, 1978. 19

Francis Wells, então membro da diretoria de Cooperação Econômica da OCDE, afirmou claramente como o relatório da Trilateral estava em consonância

15 É uma das únicas passagens em que os teóricos da interdependência mencionam explicitamente a teoria da dependência, ainda que não seus autores.

16 Umberto Colombo (1927-2006) havia sido diretor do Comitê para Políticas Científicas e Tecnológicas da OCDE (Organização para a Cooperação e Desenvolvimento Econômico), cargo que ocupou entre 1972 e 1975; proveniente do setor privado, fora diretor-geral de Pesquisa e Desenvolvimento do conglomerado alimentício Montedison, de Milão.

17 Professor de Economia da Universidade de Chicago, Johnson serviu como consultor da Agência para Desenvolvimento Internacional entre 1962 e 1968, e como membro de uma série de órgãos oficiais de consultoria do Estado nos anos de 1960.

18 Presidente da Nikko Research Center, ocupou diversos cargos de Estado no Japão voltados para pesquisa em agricultura. Também trabalhou na embaixada japonesa em Washington.

19 O relato sobre a discussão desse TFR no encontro de Bonn pode ser encontrado em OKITA, 1978. 
com a abordagem das "necessidades básicas", delineada pelo encontro de 1977 do Development Assistance Committee da OCDE, a partir da influência do World Employment Conference da OIT (Organização Internacional do Trabalho), de 1976 - denotando a conexão da Trilateral com múltiplas instituições.

Em junho de 1978, o presidente americano Jimmy Carter anuncia seu plano de estabelecer uma "Comissão sobre a fome mundial" (Commission on World Hunger - CWH), num encontro privado na Casa Branca, com membros da Comissão Trilateral. O anúncio oficial seria em setembro, no mesmo período em que saiu o TFR coordenado por Colombo. O presidente da CWH coordenaria os esforços das agências das Nações Unidas com organizações internacionais para combater a fome. Para o cargo, foi designado o trilateralista Sol Linowitz, o que mostra como as ideias trilateralistas chegaram ao topo da política externa americana no governo Carter (SKLAR, 1980, p. 493).

A partir do conceito de hegemonia que apresentamos na primeira parte deste artigo, fica claro que a proposta trilateralista, centrada no conceito de interdependência, se mostrou como uma estratégia bastante elaborada de reordenamento das organizações internacionais.

\section{Compartilhando a liderança global e incorporando o "setor privado" na reforma das organizações internacionais}

Um segundo problema dos arranjos institucionais internacionais, segundo o relatório coordenado por Bergsten em 1976, seria a falta de consistência e "liderança decisiva”. A história teria mostrado que um sistema internacional efetivo requer um "zelador", e ele precisa ser um país relativamente grande ou um grupo de países, porque somente uma entidade assim seria tanto atenta a respeito dos efeitos sistêmicos de suas próprias ações e, portanto, ciente de seu papel de zelador, quanto apta para "aceitar os efeitos políticos domésticos das ações para defender o sistema” (BERGSTEN, BERTHOIN \& MUSHAKOJI, 1976, p. 10). Os Estados Unidos, desde o primeiro pós-guerra do século XX, viveram historicamente o dilema entre priorizar os interesses domésticos e cumprir o papel de garantidor de um sistema internacional estável. A questão que o relatório se colocava era simples, embora a resposta fosse difícil: sem os Estados Unidos, quem agora poderia cumprir tal papel?

Nenhum país ou grupo de países parecia apto a desempenhar essa liderança sozinho. A única alternativa, segundo o relatório, era a "liderança coletiva" ou 
“compartilhada”. Os EUA, o Japão, a Comunidade Europeia como grupo (ou a Alemanha e talvez mais um ou dois países da Europa Ocidental) e talvez "até mesmo" um ou dois países membros da OPEP e do Terceiro Mundo pareciam os prováveis parceiros em qualquer arranjo coletivo (BERGSTEN, BERTHOIN \& MUSHAKOJI, 1976, p. 12). Aqui se revela cristalinamente a ideia de uma aliança orgânica entre os países centrais, incorporando subalternamente os países considerados mais relevantes na periferia - a qual podemos entender melhor a partir do conceito de hegemonia anteriormente apresentado.

As propostas corretas para a reforma das organizações internacionais, segundo o relatório, deveriam se centrar em cinco questões-chave: a criação de novas instituições sobre determinadas questões críticas para a interdependência, não contempladas pelas existentes; a reforma de algumas das instituições existentes; a mobilização mais efetiva de ambos os sets de instituições; a legitimação de todas as instituições através da integração de newcomers e de dropouts, além de uma melhor coordenação entre as áreas-chave, de maneira a progredir na questão da liderança global.

Segundo o relatório, as ações para atingir algumas das demandas substantivas dos países em desenvolvimento, embora condição necessária para integrá-los dentro da ordem econômica internacional, não seriam o suficiente, e um segundo passo seria prover os países em desenvolvimento “chave” com algum papel político no processo de decision making internacional. É nesse ponto que foi cogitado, no relatório, a inclusão do Brasil, do Irã e do México na OCDE (BERGSTEN, BERTHOIN \& MUSHAKOJI, 1976, p. 25).

Em adição, as instituições deveriam procurar envolver o setor privado nos países onde quer que este fosse influente. "De fato”, afirmava o relatório, "grupos privados podem frequentemente serem mobilizados para ajudar a catalisar a ação internacional” (BERGSTEN, BERTHOIN \& MUSHAKOJI, 1976, p. 24). Aqui fica claro que a ligação orgânica com o grande empresariado (eufemisticamente chamado de "setor privado") era uma condição sine qua non para a viabilidade das propostas trilateralistas. Isso revela outro viés da elaboração trilateralista: a reforma das organizações internacionais deveria transcender os encontros formais entre Estados, incorporando os chamados “atores não estatais”, especialmente os empresários, em seu cerne. Uma espécie de “diplomacia privada”, na opinião dos trilateralistas, andaria de mãos dadas com a diplomacia oficial, e não por acaso o tema das consultas internacionais mereceu um TFR próprio. 
Publicado também em 1976 e intitulado "O problema das consultas internacionais", ele foi escrito por três ex-embaixadores que serviram nos EUA: Egidio Ortona ${ }^{20}$, J. Robert Schaetzel ${ }^{21}$ e Nobuhiko Ushiba ${ }^{22}$. O relatório dos exembaixadores destacava que a seriedade e a potencialidade da consulta estavam em proporção inversa à sua formalidade, algo que iria contra a excessiva ênfase em instrumentos tais como comitês ministeriais formais. Os contatos informais e discretos seriam essenciais ao trabalho de grupos mais formais e, além disso, a informalidade permitiria que as consultas fossem feitas no devido timing da política, de modo a poder influenciar propriamente o processo decisório (ORTONA, SCHAETZEL \& USHIBA, 1976).

\section{Influências e divergências}

A análise pormenorizada da influência direta da Trilateral Commission na formatação das instituições internacionais - e na criação de novas - foge ao escopo deste artigo. Entretanto, cabe mencionar brevemente alguns exemplos da influência direta da alternativa estratégica trilateralista, como mais uma forma de demonstrar nossa afirmação inicial de que a proposta em tela constituiu a mais elaborada estratégia cosmopolita dos anos de 1970.

Além da já mencionada relação com o Banco Mundial e com outros organismos, o exemplo talvez mais evidente da influência da comissão na construção de uma organização internacional foi a criação, em 1975, da Agência Internacional de Energia (IEA, em sua sigla em inglês), que foi explicitamente sugerida em um relatório de 1974 da comissão (CAMPBELL, CARMOY \& KONDO, 1974). Segundo dois importantes estudos sobre a Trilateral Commission, a criação da agência foi um produto direto desse relatório (SKLAR, 1980, p. 472; SHOUP; MINTER, 1977, p. 83).

Diversos membros da Trilateral Commission participaram de iniciativas de encontros internacionais informais, tais como os Economic Summits em Rambouillet, na França, em 1975, e em Porto Rico, em 1976, e também de iniciativas formais como a criação da CIEC (Conference on International Economic Cooperation), em 1975. Essas iniciativas eram por eles bastante valorizadas, pois constituíam um embrião do qual poderia emergir a tão almejada "liderança coletiva”. O Comitê Rey

\footnotetext{
20 Ex-embaixador da Itália para os Estados Unidos.

21 Ex-embaixador dos Estados Unidos para as Comunidades Europeias.

22 Ex-embaixador do Japão para os Estados Unidos.
} 
da OCDE, que ajudou a lançar as bases para as Multilateral Trade Negotiations, contou com a participação de trilateralistas; bem como o "Grupo das Nações Unidas de Pessoas Eminentes”, que tentou construir, na época, uma Comissão sobre Negócios Transnacionais (Commission on Transnational Enterprises). Isso mostra como os trilateralistas estavam inseridos nas mais relevantes iniciativas internacionais do período, tanto as formais como as informais.

Não obstante, é preciso notar que não havia consenso dentro da comissão sobre inúmeros assuntos, por exemplo, se encontros como o de Rambouillet seriam a melhor saída a longo prazo. A posição oficial da comissão, que podemos encontrar em uma resolução conjunta de seu comitê executivo, publicada ainda em 2 de dezembro de 1975, aprovava a realização do encontro, ocorrido entre 16 e 18 de novembro do mesmo ano, e ressaltava sua importância especialmente no que tangia à coordenação das políticas economias domésticas entre os "governos trilaterais". Como podemos ler no Trialogue que publicou tal resolução, um comissionário teria criticado a visão "diretiva” e não multilateral de Rambouillet, o que geraria um grande "ressentimento" nos países que ficariam de fora. O encarregado de fazer um relato sobre o encontro para a comissão, Otto Lambsdorff (membro do Bundestag alemão), propôs não tornar Rambouillet uma instituição regular (TRILATERAL COMMISSION, 1976, p. 14) - opinião que acabou não prevalecendo, pois os encontros de Rambouillet e Porto Rico acabaram se tornando os embriões do G-7 (BONHOMME, 2014).

O Trialogue número 11 revela que, para alguns, a proposta de criar novas instituições internacionais, presente no relatório de Bergsten de 1976, estaria "fora de momento" e seria "ambiciosa demais". A OCDE, para eles, seria ainda a melhor estrutura para fazer os progressos possíveis. Outra divergência relacionouse com a própria composição da OCDE: como vimos, o relatório "A reforma das instituições internacionais" propunha que o Brasil e o Irã fossem convidados para ingressar na OCDE. Mas, segundo o Trialogue, muitos membros da comissão foram relutantes em aceitar tais sugestões, alegando, entre outras razões, a natureza autoritária dos regimes domésticos no Irã e no Brasil (TRILATERAL COMMISSION, 1976, p. 12-13).

Outro reflexo do dissenso dentro da Trilateral Commission foi a publicação de dois task forces sobre segurança internacional, entre 1977 e 1978. O primeiro relatório (OWEN, SHONFIELD \& HOSOYA, 1977) favorecia maior cooperação econômica e funcional com a URSS, e apoio às políticas de controle de armas; já o segundo expressava claramente uma linha de confronto explícito, refletindo, 
possivelmente, os sentimentos antissoviéticos que reascendiam massivamente nos EUA e a opinião de novos ingressantes na comissão, ligados ao complexo industrial-militar (AZRAEL, LÖWENTHAL \& NAKAGAWA, 1978).

Em 1979, três acontecimentos mudariam os rumos dessas discussões de maneira decisiva. A invasão soviética ao Afeganistão e a revolução iraniana, ambas no final daquele ano, marcariam uma virada na elaboração de política externa das chamadas "sociedades trilaterais". Uma forte mudança de humor político se deu nos Estados Unidos, que em 1980 acabaram elegendo o republicano Ronald Reagan como presidente, legitimando um discurso fortemente nacionalista e unilateralista. Com o reconhecido revés da administração Reagan no que se referia à participação dos Estados Unidos em organizações internacionais, era previsível que as propostas trilateralistas se tornassem menos influentes e aos poucos fossem obliteradas. O terceiro acontecimento veio do campo econômico: o chamado "choque Volcker" - o aumento dos juros pelo FED, o Banco Central americano - recordou para o mundo o poder dos Estados Unidos como emissor da única moeda internacional, e colocou o problema da hegemonia americana em novos patamares.

Seria muito simplista tentar enxergar na atual configuração das organizações internacionais uma "realização" ou uma "não realização" das propostas trilateralistas - tal leitura certamente beiraria o "conspiracionismo". O formato dessas organizações é foco de disputa permanente, que tem uma historicidade própria e é condicionado por inúmeros fatores objetivos, como a economia internacional, a distribuição de poder bélico, entre tantos outros. Entretanto, a configuração atual de muitas das instituições internacionais que eram alvo da terapia trilateralista indica que recomendações essenciais presentes nas elaborações da comissão permaneceram vivas nas últimas décadas. Por exemplo, a estrutura dual marcada por um inegável fortalecimento de organismos supostamente mais "técnicos", como a OMC (Organização Mundial do Comércio, o antigo GATT), em detrimento dos organismos mais amplos politicamente e de formato multiproposital, como a ONU, que, entretanto, seguem legitimando uma certa ordem internacional.

\section{Conclusões}

Demonstramos, neste artigo, como a característica institucionalista e liberal das teorias que influenciaram diretamente os relatórios da Trilateral Commission nos anos de 1970, especialmente a partir de economistas como C. F. Bergsten e de 
teóricos de relações internacionais como Joseph Nye e Robert Keohane, constituiu a coluna vertebral da proposta trilateralista para a reforma das organizações internacionais, denotando a relação orgânica entre teoria analítica e propostas normativas.

Também demonstramos, a partir da análise detalhada dos relatórios da comissão sobre as instituições internacionais nos anos de 1970, em especial entre 1976 e 1977, que os trilateralistas não estavam preocupados com mudanças de curto prazo, mas sim com formatos institucionais de longa duração: uma reorganização institucional internacional numa hegemonia de novo tipo. Diante da crise de hegemonia, tratava-se, para os trilateralistas, de oficializar o "compartilhamento" do poder nessas instituições, incorporando novos membros (newcomers) e aproximando ou neutralizando a ação dos dropouts, em especial o bloco soviético.

Mostramos como, na visão estratégica trilateralista, as linhas gerais da reforma das organizações internacionais visavam uma estratégia de longo prazo de prevenção de conflitos internacionais, muito além de uma mera reação imediata a alguns deles. Segundo os trilateralistas, o único modo de construir a tão almejada "hegemonia compartilhada" entre os países "trilaterais" seria aprofundar os mecanismos de consulta e cooperação, além do fortalecimento das instituições internacionais. Um aspecto importante desse fortalecimento seria a "despolitização" das questões internacionais e o direcionamento das "questões mais sensíveis" a organismos técnicos específicos. O aprofundamento da institucionalização de organizações internacionais exigia, na visão trilateralista, uma maior participação do "setor privado" no processo decisório, dentro de um sistema de consultas internacionais que complementasse as relações oficiais entre Estados.

Retomando a teoria crítica que apresentamos no início do artigo, podemos afirmar que se tornou evidente, para um espectro considerável de atores políticos relevantes nos anos de 1970, que a aquiescência de estratos sociais dominantes de outros Estados, de que fala Stephen Gill, é uma premissa da hegemonia no plano internacional. A proposta trilateralista para a reforma das organizações internacionais representa perfeitamente as funções descritas por Robert Cox em suas análises das instituições internacionais.

Independentemente dos sucessos e fracassos relativos das inúmeras propostas trilateralistas, bem como de suas divergências internas, o que emerge como fato notável é a reunião de representantes de altos círculos empresariais, burocráticos e políticos dos países centrais, num cenário de crise de hegemonia, com o objetivo de não apenas forjar alianças, mas também de formatar concepções fundamentais 
acerca das instituições internacionais. Enquanto as tendências recentes das relações internacionais apontam para o enfraquecimento de organizações internacionais e para um ascenso nacionalista e anticosmopolita, o projeto trilateralista merece ser relembrado: não como uma proposta normativa capaz de resolver os problemas atuais, mas como um alerta de que o leque de alternativas estratégicas num cenário de crise pode ser mais diversificado do que o que a realidade aparente sugere.

\section{Referências}

ARRIGHI, Giovanni. O longo século XX: dinheiro, poder e as origens de nosso tempo. Rio de Janeiro: Contraponto; São Paulo: Ed. Unesp, 1996.

AZRAEL, Jemery; LÖWENTHAL, Richard; NAKAGAWA, Tohru. An overview of East-West Relations. Trilateral Commission: Task-Force Report n. 15, 1978.

BOHNOMME, Noel. Sommets du G7 et régulation économique internationale dans les années 1970. Presses Universitaires de France, 2014/2, n. 157. p. 111-130.

BRZEZINSKI, Zbigniew. Entre duas eras. América: Laboratório do mundo. Rio de Janeiro: Artenova, 1971.

Bergsten, C. Fred; BERTHOIN, Georges; MUSHAKOJI, Kinhide. The Reform of International Institutions. Trilateral Commission: Task-Force Report n.11, 1976.

CAMPBELL, John; CARMOY, Guy; KONDO, Shinichi. Energy: the imperative for a trilateral approach. Trilateral Commission. Task-Force Report n. 5, 1974.

COLOMBO, Umberto; JOHNSON, D. Gale \& SHISHIDO, Toshio. Reducing malnutrition in developing countries: increasing Rice production in South and Southeast Asia. Trilateral Commission: Task-Force Report n. 16, 1978.

COOPER, Richard; KAISER, Karl; KOSAKA, Masataka. Towards a renovated international system. Trilateral Commission: Task-Force Report n. 14, 1977.

COX, Robert. Gramsci, hegemonia e relações internacionais: um ensaio sobre o método. In. GILL, Stephen. (org.). Gramsci, materialismo histórico e relações internacionais. Rio de Janeiro: UFRJ, 2007.

COX, Robert; ACOBSON, Harold. The anatomy of influence: decision making in international organization. New Haven: Yale University Press, 1973.

GARCIA, Ana Saggioro. A internacionalização de empresas brasileiras durante o governo Lula: uma análise crítica da relação entre capital e Estado no Brasil contemporâneo. Tese de doutorado. Pontifícia Universidade Católica do Rio de Janeiro, 2012.

GARDNER, Richard; OKITA, Saburo; UDINK, B.J. A Turning point in the North-South economic Relations Trilateral Commission: Task-Force Report n. 3, 1974. 
GILL, Stephen. American Hegemony and the Trilateral Commission. Cambridge: Cambridge University Press, 1990.

GILL, Stephen. (org.). Gramsci, materialismo histórico e relações internacionais. Rio de Janeiro: UFRJ, 2007.

HERZ, Monica. Teoria da Relações Internacionais no Pós-Guerra Fria. Dados, vol. 40, n. 2, Janeiro de 1997.

HERZ, Monica; HOFFMAN, Andrea Ribeiro. Organizações Internacionais: definição e história. Rio de Janeiro: Campus/Elsevier, 2004.

HUNTINGTON, Samuel P.; CROZIER, Michel; WATANUKI, Joji. The crisis of democracy: report on the governability of democracies to the Trilateral Commision. New York: New York University Press, 1975.

KEOHANE, Robert O.; NYE, Joseph. Transnational Relations and World Politics, Cambridge, Massachussets: Harvard University Press, 1971.

NOGUEIRA, João Pontes; MESSARI, Nizar. Teoria das Relações Internacionais: correntes e debates. Rio de Janeiro: Elsevier, 2005.

OKITA, Saburo. Trilateral proposal debated. Doubling Rice production in Asia. Trialogue n. 17, 1978.

ORTONA, Egidio; SCHAETZEL, J. Robert; USHIBA, Nobuhiko. The problem of international consultatios. Trilateral Commission. Task-Force Report n. 12, 1976.

OWEN, Henry; SHONFIELD, Andrew; HOSOYA, Chihiro. Collaboration with communist countries in managing global problems: an examination of the options. Trilateral Commission: Task-Force Report n.13, 1977.

PEREIRA, J.M.M. O Banco Mundial como ator político intelectual e financeiro. 1944-2008. Rio de Janeiro: Civilização Brasileira, 2010.

SHOUP, Laurence H.; MINTER, William. Imperial Brain Trust. The Council on Foreign Relations and the United States Foreign Policy. Monthly Review Press, 1977.

SKLAR, Holly (org.) Trilateralism: managing dependence and democracy. Boston: South and Press, 1980.

TRILATERAL COMMISSION. Trialogue. A bulletin of American-european-japanese affairs. $\mathrm{N}^{\circ}$ 09, dezembro de 1975/janeiro de 1976.

WALLERSTEIN, Immanuel. O declínio do poder americano. Rio de Janeiro: Contraponto, 2004. 